\title{
Continuous extrusion and rolling forming of copper strips
}

\author{
Xinbing Yun*, Mo Zhou, Tian Tian, and Ying Zhao \\ Engineering Research Center of Continuous Extrusion, Ministry of Education, Dalian Jiaotong University, Dalian 116028, P.R. China
}

Received 25 September 2015 / Accepted 5 February 2016

\begin{abstract}
Continuous extrusion and rolling technology was proposed as a new strip production technology. It conducts a hot rolling process using waste heat after continuous extrusion. The continuous extrusion and rolling forming was simulated with DEFORM-3D ${ }^{\mathrm{T}}$. Influences of extrusion wheel velocity and rolling reduction on the continuous extrusion and rolling forming were analyzed. It was shown that as extrusion wheel velocity increases, torque of extrusion wheel, chamber force and rolling force, will drop; temperature of the billet in the area of abutment which is highest will increase. As the rolling reduction is increased, torque of the extrusion wheel and force acting on the chamber decrease, while torque and force of the rolls increase. The experimental results showed that a homogeneously distributed and equiaxed grains microstructure can be formed in copper strip billets with an average grain size of about $80 \mu \mathrm{m}$, after continuous extrusion. Grains of the copper strips are stretched clearly, during rolling, along the rolling direction, to form a stable orientation. Nevertheless, the grain boundaries are still relatively clear to see.
\end{abstract}

Key words: Continuous extrusion and rolling, Copper strip, Numerical simulation, Rolling reduction

\section{Introduction}

Continuous extrusion and rolling forming technology is a burgeoning and environmental manufacturing technology. It is combined with continuous extrusion process and rolling process in a row. The principle of continuous extrusion and rolling process is that oxygen-free copper plates or strips is pressed in the groove of the extrusion wheel by coining wheel, and moves with the friction of extrusion wheel rotating, then is obstructed by the abutment, turns to the chamber. The billet fills the chamber until extruded from the die. The temperature of the strips from continuous extrusion is about $400-600{ }^{\circ} \mathrm{C}$ in the exit of die [1], there is a distance between continuous extrusion machine and rolling mill, and strips supplied by continuous extrusion could be rolled down until reaching a certain length with the temperature about $360-400{ }^{\circ} \mathrm{C}$ in the entrance of rolls.

Compared to traditional processes of cold rolling after continuous extrusion, the continuous extrusion and rolling process method has the following advantages [2-5]: (1) In this process, the frictional resistance for energy dissipation is transferred into the deformation driving force, and deformation heat and friction heat are used to reach the thermal deformation temperature of billet, so the heating process is eliminated; and (2) both the continuous extrusion and rolling completely achieve the thermal deformation of the billet, during which the dynamic

\footnotetext{
*Corresponding author: yunxb@djtu.edu.cn
}

recrystallization occurs. Therefore, the grain is significantly refined and the material property is improved; however, the size of the billet is nearly the same as that of the finished product, thus reducing the workforce of the finishing process.

Yun et al. proposed the principle of continuous extrusion and rolling technology, based on theoretical calculation and numerical simulation [6]. But it did not consider the metal flow regularity in the process with variation of the technological parameter.

In this work, the finite element model of continuous extrusion and rolling process was established by using DEFORM3D software platform in order to simulate the whole process, and the metal flow regularity was analyzed in the continuous extrusion and rolling process with variation of the technological parameter, such as the influence of extrusion wheel velocity, rolling reduction and strip size.

\section{Numerical simulation of continuous extrusion and rolling}

The DEFORM-3D software was used for the numerical simulation of continuous extrusion and rolling process of copper strips. The influence of extrusion wheel velocity and rolling reduction on the continuous extrusion and rolling forming process were analyzed. The temperature of billet, effective-stress of billet, torques of extrusion wheel and rolls, force of chamber, rolling force were compared and studied during forming. 


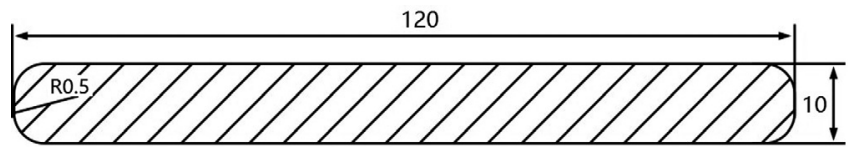

Figure 1. Cross-sectional shape of the rolled strip.

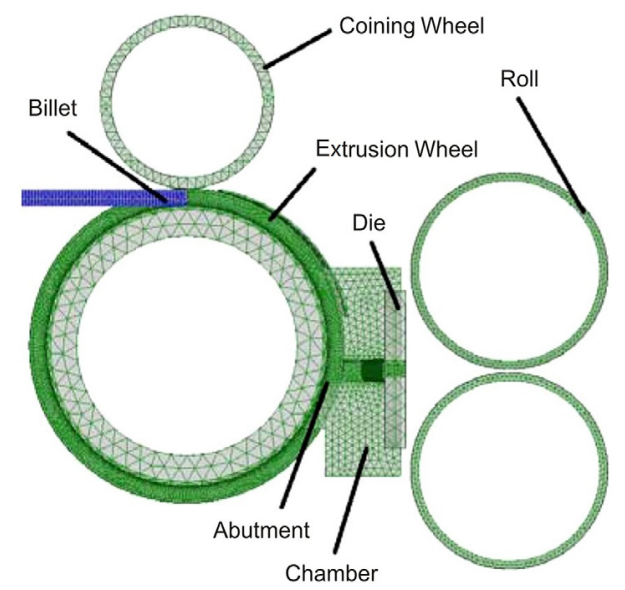

Figure 2. Finite element geometric model.

The size of a copper strip produced by continuous extrusion process is depicted in Figure 1.

The finite element simulation model which was established by using TLJ400 continuous extrusion machine and the roll with diameter of $250 \mathrm{~mm}$ as the model is depicted in Figure 2, where the representative geometry parameters are indicated. To save time and reduce the computer storage capacity, $1 / 2$ of the integral model was used for the simulations based on the symmetry $[7,8]$.

In this work, the rigid viscoplastic finite element method was used. The billet was set as the rigid-plastic body, whereas the die and other parts were set as rigid bodies. The shear friction driving model was used for the friction between the contact surfaces of the billet and the die. All of the initial parameters in numerical simulation are shown in Table 1 [9-12].

\section{Simulation results and analysis}

\subsection{Influences of the extrusion wheel velocity on the continuous extrusion and rolling forming}

Extrusion wheel velocity was set to $6 \mathrm{r} / \mathrm{min}, 9 \mathrm{r} / \mathrm{min}$, $12 \mathrm{r} / \mathrm{min}$ for the numerical simulations. Comparison of temperature, effective-stress, torque of extrusion wheel and rolling, force of chamber, and rolling force are analysed in different extrusion wheel velocity.

It can be observed that the temperature lines in the continuous extrusion and rolling process are escalating trend with extrusion wheel velocity increased in Figure 3. The temperature of billet in the area of abutment is hottest which was increased from $787{ }^{\circ} \mathrm{C}$ to $883{ }^{\circ} \mathrm{C}$, temperature of billet in the area of chamber is ascended from $604{ }^{\circ} \mathrm{C}$ to $688{ }^{\circ} \mathrm{C}$, temperature of billet in the area of exit of die is risen from $537{ }^{\circ} \mathrm{C}$ to $620{ }^{\circ} \mathrm{C}$, and temperature of billet in the area of rolls is from
Table 1. The initial parameters of numerical simulation.

\begin{tabular}{cc}
\hline Condition & Value \\
\hline Material of billet & Copper \\
Material of tool and die & AISI-H13 \\
Diameter of billet $(\mathrm{mm})$ & $\Phi 20$ \\
Initial temperature of billet $\left({ }^{\circ} \mathrm{C}\right)$ & 20 \\
Initial temperature of tool and die $\left({ }^{\circ} \mathrm{C}\right)$ & 450 \\
Rotation velocity of extrusion wheel $(\mathrm{rpm})$ & $6,9,12$ \\
Friction factor of billet and extrusion wheel & 0.95 \\
Friction factor of billet and guide roller & 0.05 \\
Friction factor of billet and chamber and die & 0.3 \\
Friction factor of billet and roller & 0.35 \\
Conductivity of billet $(\mathrm{N} / \mathrm{s} \mathrm{K})$ & 30 \\
Heat capacity of billet $(\mathrm{N} \mathrm{m} / \mathrm{K})$ & 0.3 \\
\hline
\end{tabular}

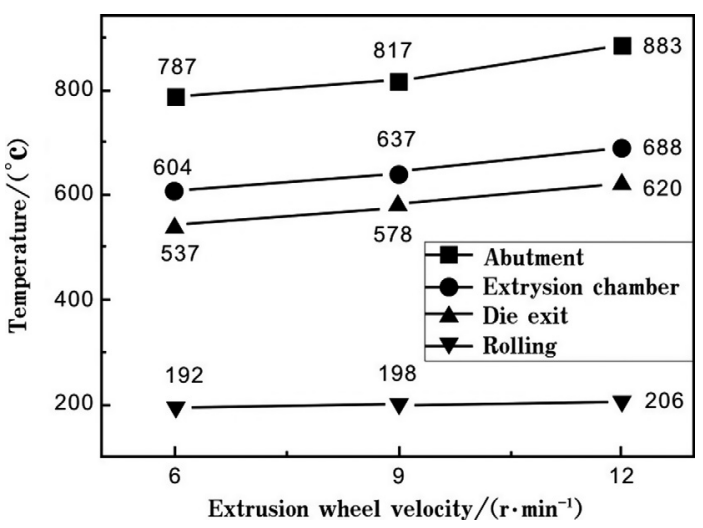

Figure 3. Effects of velocities of extrusion wheel on temperature.

$192{ }^{\circ} \mathrm{C}$ up to $206{ }^{\circ} \mathrm{C}$. What makes increment of temperature of billet is that speed difference between billet and extrusion wheel become bigger with greater velocity of extrusion wheel, work from extrusion wheel to qualities of heat of billet is increased, extent of plastic transformation of billet is severer with extrusion wheel velocity increased. Due to temperature of billet in the continuous extrusion process is risen, the temperature in the rolling process is also increased, and the abutment and chamber will be suffered more abraded. As a result, it's not advisable to choose overlarge velocity of extrusion wheel for continuous extrusion and rolling process.

Figure 4 is depicted that effective-stress of billet is risen slightly since extrusion wheel velocity increased. As extrusion wheel velocity increased, temperature of billet is higher, flow velocity of billet is rapider, effective-stress is also ascended.

From Figure 5, it can be seen that the torque of extrusion wheel will be dropped from $5.44 \mathrm{~N} \mathrm{~mm}$ to $4.80 \mathrm{~N} \mathrm{~mm}$ when extrusion wheel is increased from $6 \mathrm{r} / \mathrm{min}$ to $12 \mathrm{r} / \mathrm{min}$, which because increase of temperature of billet makes extent of plastic transformation of billet severer, work of billet to plastic transformation needed from extrusion wheel is reduced.

Because of resistance of strip suffered by rolls decreasing, torque of rolls is also dropped from $16.08 \mathrm{~N} \mathrm{~mm}$ to $12.96 \mathrm{~N} \mathrm{~mm}$ with extrusion wheel increased $6 \mathrm{r} / \mathrm{min}$ to $12 \mathrm{r} / \mathrm{min}$ (Figure 6).

It can be figured out, from Figures 7 and 8, that the values of force of chamber and rolling force lines are all falling trend with extrusion wheel velocity increased. The value of force of 


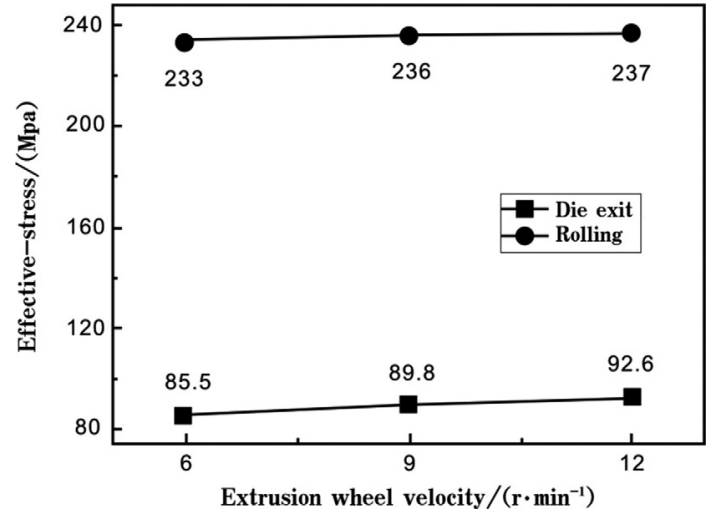

Figure 4. Effects of velocities of extrusion wheel on effectivestress.

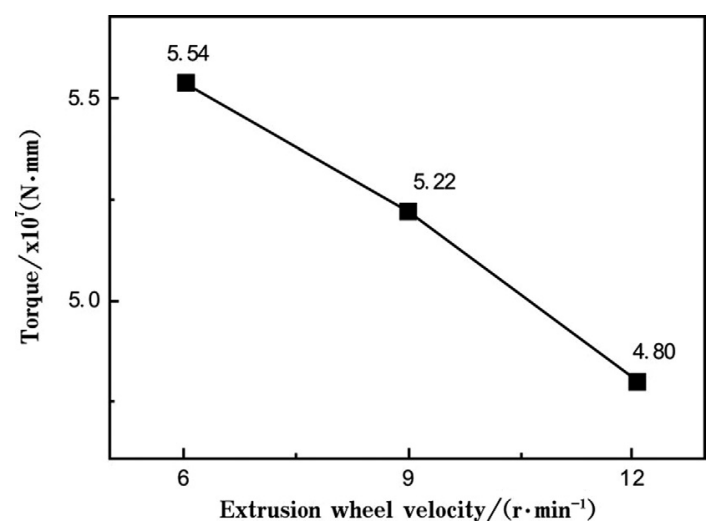

Figure 5. Effects of velocities of extrusion wheel on torque of extrusion wheel.

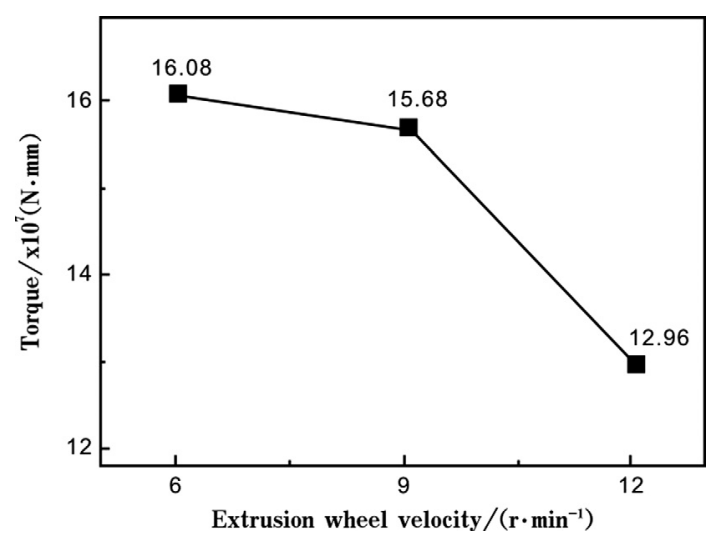

Figure 6. Effects of velocities of extrusion wheel on torque of roll.

chamber is dropped from $3.89 \times 10^{5} \mathrm{~N}$ to $2.92 \times 10^{5} \mathrm{~N}$, which as a result of resistance power of plastic transformation of billet is reduced as temperature of billet risen. And value of rolling force is decreased from $1060 \mathrm{kN}$ to $804 \mathrm{kN}$. We can draw a conclusion that rolling process will become easy with rapider velocity of extrusion wheel, but the rapider velocity of extrusion wheel, the higher temperature of billet in the

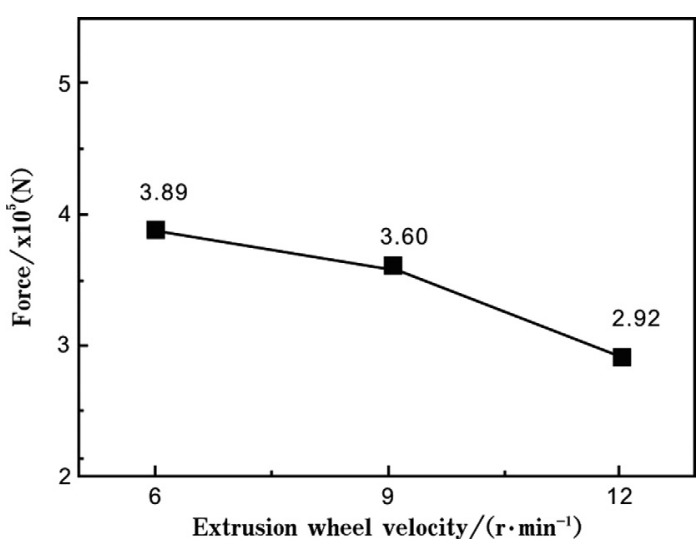

Figure 7. Effects of velocities of extrusion wheel on force of chamber.

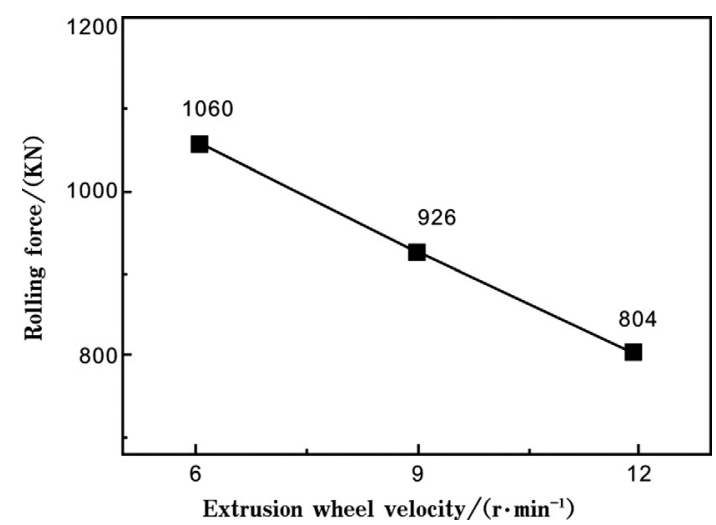

Figure 8. Effects of velocities of extrusion wheel on rolling force.

process, the higher temperature of abutment, the less working life of the moulds.

\subsection{Influences of the rolling reduction on the continuous extrusion and rolling forming}

The value of rolling reduction is one of the most important parameters in the process of continuous extrusion and rolling. In this part, transformation regularity of the size of strips will be discussed which are presented by continuous extrusion and the size is $120 \times 10 \mathrm{~mm}^{2}$. The rolling reduction respectively are $2 \mathrm{~mm}, 4 \mathrm{~mm}, 6 \mathrm{~mm}, 8 \mathrm{~mm}$.

Figure 9 depicts temperature of billet is decreased when rolling reduction is increased. The temperature of billet in the area of abutment is hottest which is dropped from $822{ }^{\circ} \mathrm{C}$ to $813{ }^{\circ} \mathrm{C}$, temperature of billet in the area of chamber is fell from $650{ }^{\circ} \mathrm{C}$ to $629^{\circ} \mathrm{C}$, temperature of billet in the area of exit of die is descended from $585{ }^{\circ} \mathrm{C}$ to $563{ }^{\circ} \mathrm{C}$, and temperature of billet in the area of rolls is from $206{ }^{\circ} \mathrm{C}$ down to $187^{\circ} \mathrm{C}$

Owing to temperature of billet in the continuous extrusion decreased, effective-stress of billet in the area of exit of die is increased in Figure 10. However effective-stress of billet in the area of rolls is dropped, because resistance power from rolls to 


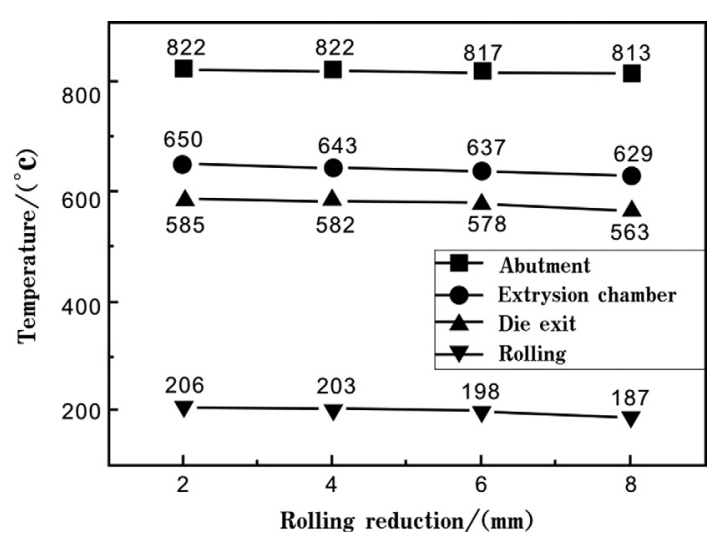

Figure 9. Effects of rolling reduction on temperature.

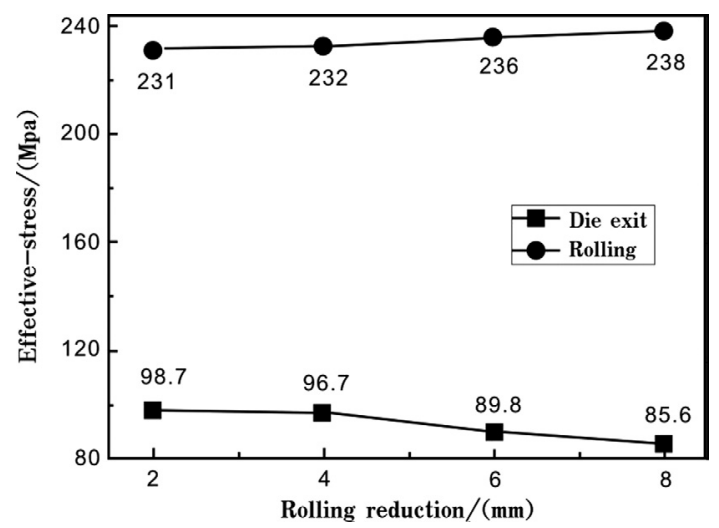

Figure 10. Effects of rolling reduction on effective-stress.

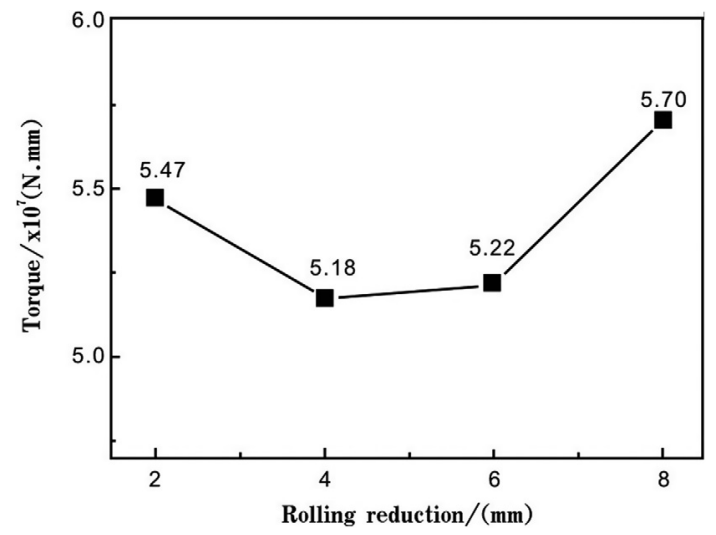

Figure 11. Effects of rolling reduction on torque of extrusion wheel.

billet is reduced as reduction decreased, which makes billet flowing harder and more slowly.

It can be obviously observed that value of torque of extrusion wheel and force of chamber is declined at first, then ascended following in Figures 11 and 12. When rolling reduction is from $2 \mathrm{~mm}$ up to $4 \mathrm{~mm}$, torque of extrusion wheel is descended from $5.47 \mathrm{~N} \mathrm{~mm}$ to $5.18 \mathrm{~N} \mathrm{~mm}$, and force of chamber is from $4.79 \times 10^{5} \mathrm{~N}$ to $3.15 \times 10^{5} \mathrm{~N}$. When rolling reduction is from $4 \mathrm{~mm}$ up to $8 \mathrm{~mm}$, torque of extrusion wheel

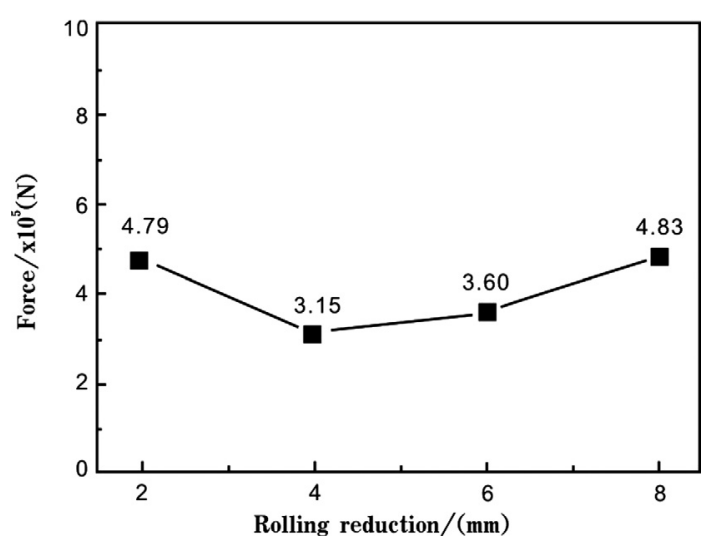

Figure 12. Effects of rolling reduction on force of chamber.

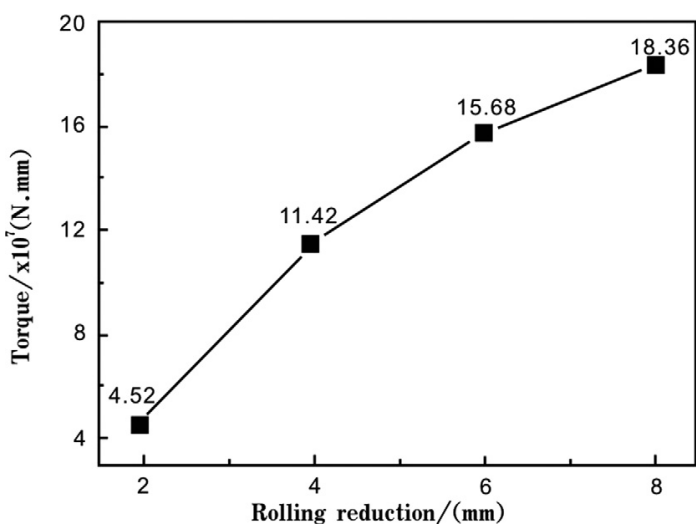

Figure 13. Effects of rolling reduction on torque of roll.

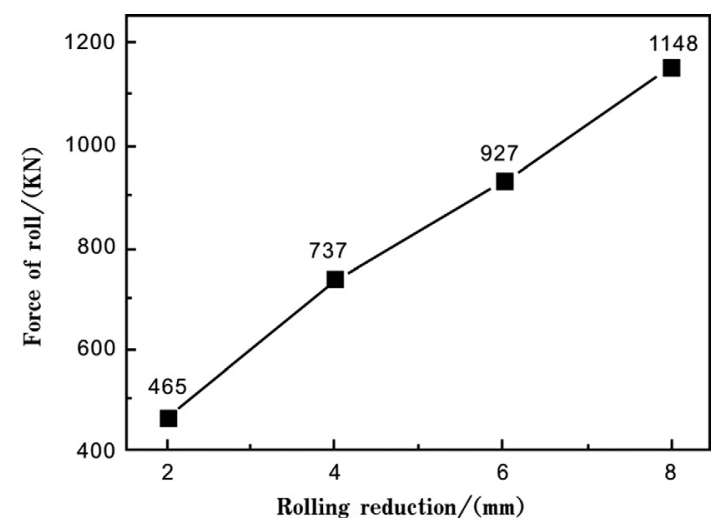

Figure 14. Effects of rolling reduction on rolling force.

is increased from $5.18 \mathrm{~N} \mathrm{~mm}$ to $5.70 \mathrm{~N} \mathrm{~mm}$, and force of chamber is from $3.15 \times 10^{5} \mathrm{~N}$ to $4.83 \times 10^{5} \mathrm{~N}$.

While value of torque and stress of rolls are risen accompanied by rolling reduction increased. Torque of rolls in Figure 13 is increased from $4.52 \mathrm{~N} \mathrm{~mm}$ to $18.36 \mathrm{~N} \mathrm{~mm}$, as rolling reduction increasing from $2 \mathrm{~mm}$ to $8 \mathrm{~mm}$. At the same time, force of rolls in Figure 14 are risen from $465 \mathrm{kN}$ to $1148 \mathrm{kN}$. In other words, it is not suitable for rolling process to take overlarge rolling reduction, if not, service life of rolls will be influenced. 


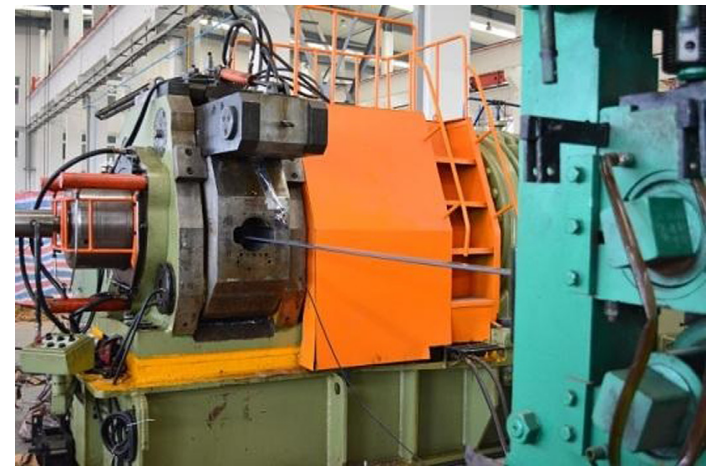

Figure 15. Experiment of continuous extrusion and rolling.

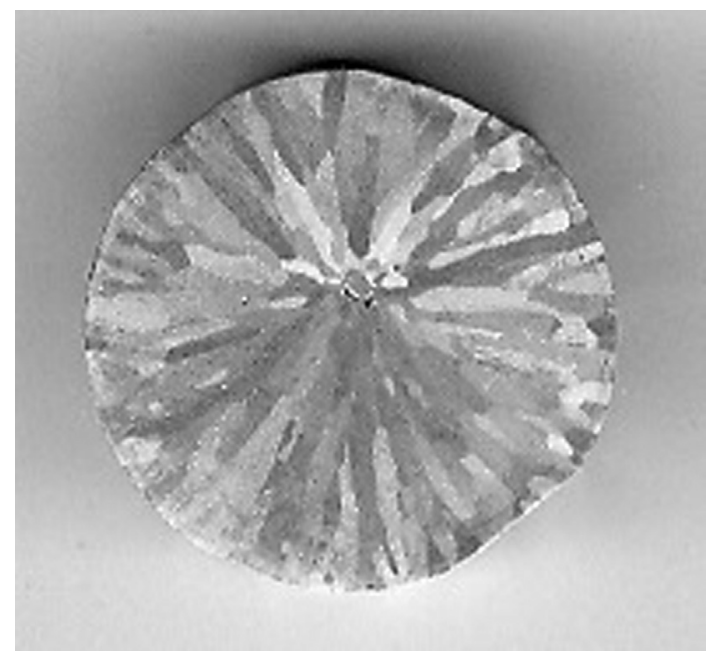

Figure 16. The billet.

\section{Experiment}

\subsection{Experimental procedures}

In the experiment, TLJ400 continuous extrusion machine and rolling mill with a diameter of $250 \mathrm{~mm}$ were used for continuous extrusion and rolling process, (Figure 15). The wheel speed was $5 \mathrm{rpm}$, the size of extrusion slab was $120 \mathrm{~mm} \times 10 \mathrm{~mm}$ and the rolling reduction was $4 \mathrm{~mm}$.

The specimens in extrusion wheel groove, deformation chamber, after extrusion and after rolling were taken out and prepared by wire cutting along the longitudinal direction. Metallographic specimens were corroded by compositing acid $(\mathrm{FeCl} 3+\mathrm{HCl})$ after furbishing and polishing. Microstructures were observed under the OLYMPUS BX41M metalloscope.

\subsection{Results and discussion}

The billet of continuous extrusion and rolling exhibited typical casting structure of the upward as-cast copper rod with diameter $\Phi 20 \mathrm{~mm}$. The average size of grain was over $1 \mathrm{~mm}$, the microstructure at the middle and adge is small equiaxed grains and oversize column crystal respectively (Figure 16).

Figure 17 shows the microstructure of copper after continuous extrusion forming. A homogeneously distributed and

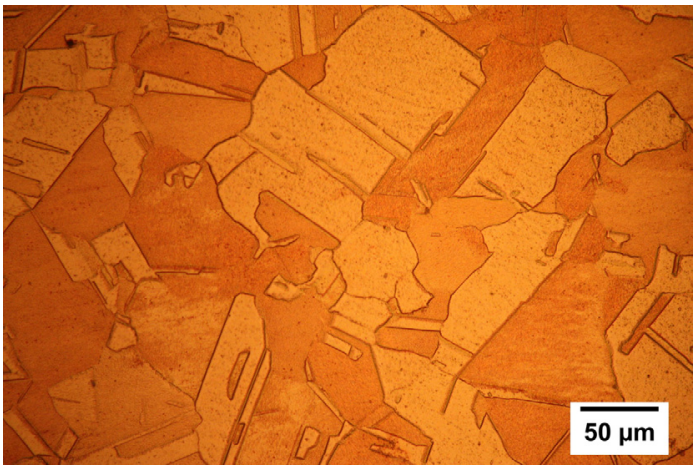

Figure 17. Copper strips of continuous extrusion.

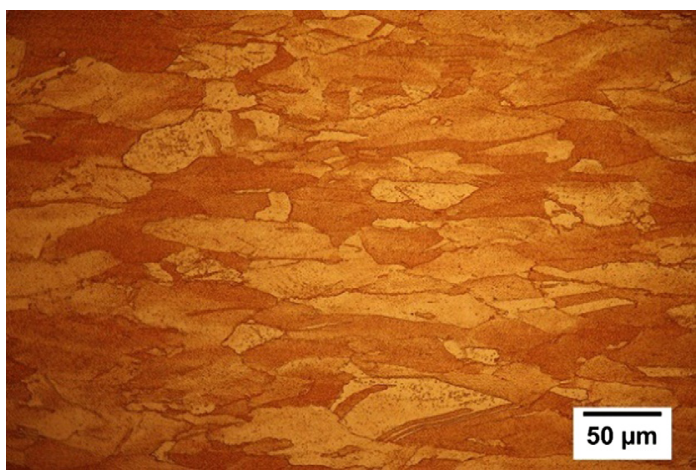

Figure 18. Microstructure of a copper strip.

equiaxed grains microstructure can be found in the copper strip billet with a grain size of about $80 \mu \mathrm{m}$.

Within the grains, twins can be observed clearly. These twins were annealing twins instead of deformation twins. This was because that copper is a face-centered cubic metal which symmetry is high. Copper has more slip systems and is easy to slip. It is difficult for copper to occur twinning in the deformation to produce deformation twins, except at very low temperature which is extremely hard to slip. The annealing twins is a kind of growing twins formed during grain growth. When the grains are grown by grain boundary migration, atomic layer stacking order of the grain boundary corner accidental wrong heap, there will be coherent twin boundaries, followed by the formation of annealing twins in the grain boundary corner. Stacking fault energy of copper is low and it is easy to form annealing twins [13].

The grains of the copper strip after rolling were stretched obviously along the rolling direction to form a stable orientation, but the boundaries were still relatively clear, as shown in Figure 18.

\section{Conclusions}

Based on the research conducted, the following conclusions may be drawn:

1. As the extrusion wheel velocity increases from $6 \mathrm{r} / \mathrm{min}$ to $12 \mathrm{r} / \mathrm{min}$, torque of the extrusion wheel will be 
reduced from $5.44 \mathrm{~N} \mathrm{~mm}$ to $4.80 \mathrm{~N} \mathrm{~mm}$, force on the chamber dropped from $3.89 \times 105 \mathrm{~N}$ to $2.92 \times 105 \mathrm{~N}$, and rolling force decreased from $1060 \mathrm{kN}$ to $804 \mathrm{kN}$. Temperature of the billet in the area of abutment where the temperature is highest increases from $787^{\circ} \mathrm{C}$ to $883{ }^{\circ} \mathrm{C}$.

2. As the rolling reduction is increased from $2 \mathrm{~mm}$ to $8 \mathrm{~mm}$, torque of the extrusion wheel descends from $5.47 \mathrm{~N} \mathrm{~mm}$ to 5.18 and force of the chamber from $4.79 \times 105 \mathrm{~N}$ to $3.15 \times 105 \mathrm{~N}$, while torque of the rolls increases from $4.52 \mathrm{~N} \mathrm{~mm}$ to $18.36 \mathrm{~N} \mathrm{~mm}$, and the force of rolls from $465 \mathrm{kN}$ to $1148 \mathrm{kN}$.

3. A homogeneously distributed and equiaxed grains microstructure can be formed in copper strip billets with an average grain size of about $80 \mu \mathrm{m}$ after continuous extrusion. Grains of the copper strip are stretched during rolling obviously, along the rolling direction, to form a stable orientation, and the boundaries are still relatively clear to see.

High-precision copper strips can be widely used in the fields like electronic materials, connectors, car terminals, coaxial cables, transformers, lead frames, and so on. Since continuous extrusion and rolling has obvious merits such as a short process chain, lower energy-consumption, higher quality, environmentally beneficial, and so on, it is certain that it will be used to replace traditional processes for producing copper belts. Therefore, it has excellent application prospects.

Acknowledgements. The work reported in this paper was supported by the National Natural Science Foundation of China (No.
51175055) and the Doctoral Program of the Ministry of Education of China (No. 20132124110003).

\section{References}

1. C.D. Chu, et al., Mechanical Science and Technology 20 (2001) 556-557.

2. Y.L. Cheng, et al., Journal of Plasticity Engineering 21 (2014) 77-81.

3. H.Y. Zhang, et al., Casting Forging Welding 23 (2010) 213-215.

4. X.B. Yun, et al., Journal of Plasticity Engineering 18 (2011) 2-5.

5. P.Y. Wu, et al., Transactions of Nonferrous Metals Society of China 17 (2007) 280-286.

6. X.B. Yun, et al., Transactions of Nonferrous Metals Society of China 23 (2013) 1108-1113.

7. X. Chen, et al., Journal of Plasticity Engineering 17 (2010) 68-72.

8. X. Cao, et al., Forging \& Stamping Technology 38 (2013) 91-95.

9. B. Li, et al., AIP Conference Proceedings 1532 (2013) 918-923.

10. Y.H. Kim, et al., Journal of Materials Processing Technology 97 (2000) 153-157.

11. Z.X. Fan, et al., Journal of Plasticity Engineering 15 (2008) 136-141.

12. Y.H. Kim, et al., Journal of Materials Processing Technology 80-81 (1998) 671-675.

13. S. Xia, et al., Chinese Journal of Nature 32 (2010) 94-100.

Cite this article as: Yun X, Zhou M, Tian T \& Zhao Y: Continuous extrusion and rolling forming of copper strips. Manufacturing Rev. $2016,3,7$. 